\title{
Nonadherence to treatment recommendations is a factor contributing to the clinical failure of daptomycin: Cohort study in Brazil
}

\author{
Tathiana Silva de Souza Martins (in memoriam) ${ }^{1}$, Albert Figueras $^{(22}$, \\ Luana dos Reis de Souza ${ }^{3}$, Keila Cristina Oliveira dos Santos ${ }^{\circledR 3}$, \\ Elaine Machado de Oliveira ${ }^{(* 4}$, Silvia Regina Secoli ${ }^{\circledR 5}$ \\ ${ }^{1}$ Safety Patient Committee, National Institute of Orthopedic Surgery, Rio de Janeiro, \\ Brazil, ${ }^{2}$ Pharmacology Department, Autonomous University of Barcelona, Barcelona, \\ Spain, ${ }^{3}$ Pediatric Institute Martagão Gesteira, Rio de Janeiro, RJ, Brazil, ${ }^{4}$ Postgraduate \\ Nursing Program in Adult Health, University of São Paulo, School of Nursing, Sao Paulo, \\ SP, Brazil, ${ }^{5}$ School of Nursing, University of São Paulo, São Paulo, SP, Brazil
}

\begin{abstract}
To evaluate the clinical outcomes of daptomycin therapy and adherence to treatment recommendations, a retrospective cohort study was conducted with patients that received daptomycin during the period of the study. The adherence and nonadherence to clinical guidelines were assessed through organism identification, dose and time of treatment, management of bacteremia, and vancomycin treatment failure. A multiple logistic regression model analyzed the association between independent variables and clinical success (dependent variable), considering 5\% of statistical significance. The study presented 52 patients who received daptomycin for the treatment of bacteremia $(21.1 \%)$ or infections (osteomyelitis [63.5\%], synovial fluid [15.4\%]). Most patients (86.5\%) received daptomycin as the second line of treatment, and $51.9 \%$ achieved clinical success. The patients had a better chance of clinical success when they followed the guideline indications $(\mathrm{OR}=16.86 ; 95 \% \mathrm{CI}=1.45-195.88)$ and the medication was prescribed by a specialist in infectious diseases $(\mathrm{OR}=4.84 ; 95 \% \mathrm{CI}=1.11$ 21.09). The study demonstrated lower clinical success than that described in the literature because of patients who were not eligible according to the clinical guidelines. Adherence to recommendations and appropriate prescription of reserve antibiotics is important in limiting early resistance, and avoiding clinical failure and unnecessary expenditure.
\end{abstract}

Keywords: Daptomycin. Post marketing. Gram-positive bacterial infections. Orthopedic.

\section{INTRODUCTION}

Bone and joint infections (e.g., osteomyelitis, septic arthritis, and prosthetic joint infections) are produced mostly by Gram-positive agents, especially Staphylococcus aureus and Enterococcus. These are complicated infections that are difficult to control

*Correspondence: E. M. Oliveira, Programa de Pós-Graduação em Enfermagem na Saúde do Adulto, Universidade de São Paulo, Escola de Enfermagem, São Paulo, SP, Brasil, Avenida Dr. Éneas de Carvalho Aguiar, 419, Cep:05403-000, São Paulo-SP. Telefone: 11979626296. Email:elainemachado@usp.br and generally require surgical interventions and long antibiotic treatments (Davis, 2005; Rice, Vigo, 2009). Several years ago, daptomycin was marketed as a promising bactericidal agent for many infectious conditions, including those seen in orthopedic hospitals.

Daptomycin is a lipopeptide antibiotic for the treatment of serious Gram-positive infections involving S. aureus, Enterococcus faecalis, and Enterococcus faecium, including vancomycin-resistant strains and methicillin-resistant $S$. aureus (MRSA) (Vilhena, Bettencourt, 2012). In 2003, the US Food and Drug Administration (FDA) approved it for the treatment of 
skin and soft-tissue infections produced by Gram-positive coccus and for the treatment of $S$. aureus bacteremia due to infectious endocarditis (Sakoulas, 2009). The European Medicines Agency (EMA) recommends this antibiotic for Gram-positive bacterial infections, soft tissue infections, endocarditis, and bacterial bacteremia (European Medicines Agency, 2017).

A recent meta-analysis based on thirteen randomized controlled trials comparing daptomycin with other antimicrobials (e.g., vancomycin, teicoplanin, gentamycin) found that the efficacy of daptomycin was similar to the comparators with the intention to treat applied (He et al., 2014).

The Cubicin Outcomes Registry and Experience (CORE) and the European section (EUCORE) are two big ongoing, retrospective, post-marketing, noncomparative databases of daptomycin use in patients that had received at least one daptomycin dose. One of its main results was the finding of $80 \%$ daptomycin clinical success in patients with osteomyelitis (Gonzalez-Ruiz et al., 2011; Liang et al., 2014).

Orthopedic patients can benefit from daptomycin, as high rates of success have been reported in osteomyelitis and osteoarticular infections due to MRSA (Liang et al., 2014). A case-control study carried out in patients with osteomyelitis (involving MRSA or not) showed that less recurrent infections during the six months following the end of antibiotics were recorded among those patients receiving daptomycin as compared with those receiving other antibiotics (Moenster et al., 2012).

In general, daptomycin is recommended as a therapeutic option in cases of MRSA osteomyelitis or Gram-positive bacteremia, among other indications, mostly as an alternative to glycopeptides (such as vancomycin) or penicillin allergy (Liu et al., 2011; Cosgrove, Avdic, Dzintars, 2015). In any case, the general recommendation is to prescribe daptomycin after discussion with an infectious diseases specialist to increase the chances of good results (Rae, 2014; Esposito et al., 2016) and take into account elements such as microbiology data (e.g., culture, MIC).

In 2009, daptomycin was authorized in Brazil for the treatment of complicated infections of skin and soft tissue caused by Gram-positive bacteria (dosing $=4 \mathrm{mg} / \mathrm{kg}$ once daily over 7-14 days or until the infection is resolved) and infection by $S$. aureus, including those associated with right-side infectious endocarditis $($ dosing $=6 \mathrm{mg} / \mathrm{kg}$ once daily for $14-42$ days) (Anvisa, 2017).
In 2014, 1,500 doses of daptomycin were dispensed at the National Institute of Orthopedic Surgery (INTO) of Rio de Janeiro, Brazil, a 310-bed specialized center. That year, the cost of this antibiotic amounted US $\$ 162,312.0$ a figure that represented $3.6 \%$ of the total pharmaceutical expenditure of the INTO. Due to the restrictive conditions on the use of daptomycin, as well as its high price, a study was carried out to describe all the patients that received daptomycin while admitted to this orthopedic research hospital.

Daptomycin was introduced in the INTO in 2009, but its prescription pattern was not assessed until the time of this study and there are not enough results in Brazil.

The objectives of this study were to evaluate the clinical outcomes of daptomycin therapy and the adherence to treatment recommendations.

\section{MATERIAL AND METHODS}

The study was carried out in the National Institute of Orthopedic Surgery (INTO) in Rio de Janeiro, Brazil. The institution is a 310-bed specialized tertiary hospital that performs highly complex surgeries in orthopedics; the occupancy rate is $75 \%$ annually.

\section{Compliance with ethical standards}

This study was approved by the Ethics Committee of National Institute of Orthopedic Surgery (INTO) with protocol number 00045.0.305.000-11. All ethical requirements were followed for the study according to resolution number 466/2012 involving studies with human beings in Brazil.

\section{Design and selection inclusion criteria}

A retrospective cohort study was conducted among those patients admitted to the National Institute of Orthopedic Surgery (INTO) between January 2010 and December 2014. The nonprobabilistic sample of convenience included all patients admitted to the institution, according to the following inclusion criteria: 18 years old or more, any number of hospitalization days, and administration of daptomycin. 


\section{Collection of information and definition of the variables}

Demographic, microbiological, and clinical outcome data, as well as information on antimicrobial treatment, were collected using a standardized case report form and were collected directly from the patient's records.

The independent variables were reason for hospitalization, age, gender, number of underlying diseases, number of concomitant drugs, type of infection, microbiological results, previous and concomitant antibiotic therapy, previous and concomitant betalactam therapy, concomitant antibiotic therapy, and daptomycin therapy.

The dependent variable or the outcome of patients was already defined in previous published studies from a clinical and microbiological standpoint, according to the following criteria:

"clinical success" or "total response" corresponds to a cure and/or microbiologically negative samples at the end of treatment (Liu et al., 2011; Marc et al., 2014).

"Treatment failure" included the following (Marc et al., 2014): persistence of the infectious syndrome despite daptomycin treatment and requiring a modification of the antibiotic therapy; and death of the patient, whatever the cause. In the present study it was considered whether death was attributable to the infectious syndrome or not, according to the clinician, and/or to an adverse effect attributable to the agent.

"Adherence and nonadherence" to clinical guidelines (CGs) or recommendations was assessed by taking into account the appropriate use of daptomycin that was based on the identification of the organism (e.g., bacteremia with suspected MRSA, osteomyelitis caused by MRSA with a vancomycin MIC $>1.5 \mathrm{mg} / \mathrm{mL}$, and coagulase-negative staphylococcal infections where the vancomycin MIC $\geq 4 \mathrm{mg} / \mathrm{mL}$ ), dose and time of therapy according to the site of infection, management of persistent MRSA bacteremia, and vancomycin treatment failures. In case a consideration described in the clinical guidelines was not followed, the condition was classified as "nonadherence" (Liu et al., 2011).

Regarding indications of use, it was considered an "off-label prescription" when daptomycin was given to patients presenting an infection not appearing in the summary of product characteristics (SPCs) approved by the Brazilian Medicines Agency (ANVISA). The indications of use of daptomycin approved by ANVISA in Brazil did not differ from those approved by the FDA and EMA.

\section{Statistical analysis}

The demographic and clinical characteristics associated with the therapeutic response were compared using a bivariate analysis. To compare categorical variables, clinical success, and treatment failure, a chisquare test and Fisher's exact test were used. For the association of variables with clinical success (dependent variable), a multiple logistic regression model was used, which indicated the chances of clinical success through an odds ratio. We used SPSS and a 5\% significance level in all analyses.

\section{RESULTS}

During the study period, 52 patients (33 women; $63.5 \%$ ) admitted to the INTO were prescribed daptomycin for the treatment of bacteremia (11 patients; $21.1 \%$ ) or osteoarticular infections (osteomyelitis 33; $63.5 \%$, and synovial fluid $8 ; 15.4 \%$ ) and followed the inclusion criteria. Table I shows that the most frequent comorbidities were arterial hypertension (26 patients, $50.0 \%$ ) and type 2 diabetes mellitus (7 patients; 13.4\%). The mean of hospitalization was 67 days $(\mathrm{SD}=48.9)$. More than a half of patients of the cohort showed clinical success $(27 ; 51.9 \%)$, while treatment failure was recorded in the remaining 25 (48.1\%), being that five patients died $(9.6 \%)$.

TABLE I - Demographic and clinical characteristics of the 52 patients undergoing daptomycin therapy. Brazil, 2010-14

\begin{tabular}{lcc}
$\begin{array}{l}\text { Characteristics } \\
\text { of patients }\end{array}$ & $\begin{array}{c}\text { Clinical } \\
\text { success } \\
(\mathbf{N}=\mathbf{2 7})\end{array}$ & $\begin{array}{c}\text { Treatment } \\
\text { failure } \\
(\mathbf{N}=\mathbf{2 5})\end{array}$ \\
\hline Gender & & \\
Female & $14(51.8)$ & $19(76.0)$ \\
Male & $13(48.2)$ & $6(24.0)$ \\
\hline
\end{tabular}

Age (years)

$\mathrm{NS}^{1}$

$\begin{array}{lll}<65 & 17(62.9) \quad 10(40.0)\end{array}$

$\geq 65 \quad 10(37.1) \quad 15(60.0)$ 
TABLE I - Demographic and clinical characteristics of the 52 patients undergoing daptomycin therapy. Brazil, 2010-14

\begin{tabular}{lccc}
\hline $\begin{array}{l}\text { Characteristics } \\
\text { of patients }\end{array}$ & $\begin{array}{c}\text { Clinical } \\
\text { success } \\
\mathbf{( N = 2 7 )}\end{array}$ & $\begin{array}{c}\text { Treatment } \\
\text { failure } \\
(\mathbf{N}=\mathbf{2 5})\end{array}$ & p-value* $^{*}$ \\
\hline $\begin{array}{l}\text { Number of } \\
\text { underlying diseases }\end{array}$ & $13(48.1)$ & $3(12.0)$ & \\
0 & $14(51.9)$ & $22(88.0)$ & \\
$1-2$ & & & \\
\hline $\begin{array}{l}\text { Hospitalization } \\
\text { (days) }\end{array}$ & $1(3.7)$ & 0.005 & \\
$1-13$ & $4(14.8)$ & $6(24.0)$ & \\
$14-34$ & $8(29.7)$ & $6(24.0)$ & \\
$35-55$ & $14(51.8)$ & $13(52.0)$ & \\
$\geq 56$ & &
\end{tabular}

\begin{tabular}{llll}
$\begin{array}{l}\text { Number of } \\
\text { concomitant drugs }\end{array}$ & & $\mathrm{NS}^{1}$ \\
$<10$ & $12(44.5)$ & $10(40.0)$ & \\
$\geq 10$ & $15(55.5)$ & $15(60.0)$ & \\
\hline Types of infection & & & 0.024 \\
Bone & $21(77.8)$ & $12(48.0)$ & \\
Synovial fluid & $1(3.7)$ & $7(28.0)$ & \\
Bacteremia & $5(18.5)$ & $6(24.0)$ & \\
\hline
\end{tabular}

Microbiological

results

$\mathrm{NS}^{1}$

\begin{tabular}{lcc} 
MRSA $^{2}$ & $17(63.0)$ & $12(48.0)$ \\
$\begin{array}{l}\text { S. aureus coagulase } \\
\text { negative }\end{array}$ & $6(22.2)$ & $4(16.0)$ \\
Others & $4(14.8)$ & $9(36.0)$ \\
\hline
\end{tabular}

\begin{tabular}{llll}
\hline $\begin{array}{l}\text { Previous antibiotic } \\
\text { therapy }\end{array}$ & & $\mathrm{NS}^{1}$ \\
Yes & $21(77.8)$ & $24(96.0)$ & \\
No & $6(22.2)$ & $1(4.0)$ & \\
\hline
\end{tabular}

TABLE I - Demographic and clinical characteristics of the 52 patients undergoing daptomycin therapy. Brazil, 2010-14

\begin{tabular}{lccc}
\hline $\begin{array}{l}\text { Characteristics } \\
\text { of patients }\end{array}$ & $\begin{array}{c}\text { Clinical } \\
\text { success } \\
(\mathbf{N}=27)\end{array}$ & $\begin{array}{c}\text { Treatment } \\
\text { failure } \\
(\mathbf{N}=25)\end{array} \quad$ p-value* \\
\hline
\end{tabular}

Previous beta-

lactam therapy

$\mathrm{NS}^{1}$

$\begin{array}{lll}\text { Yes } & 16(59.0) & 16(64.0) \\ \text { No } & 11(41.0) & 9(36.0)\end{array}$

Concomitant

antibiotic therapy

$\mathrm{NS}^{1}$

$\begin{array}{lll}\text { Yes } & 20(74.0) & 19(76.0) \\ \text { No } & 7(26.0) & 6(24.0)\end{array}$

Concomitant beta-

lactam therapy

$\mathrm{NS}^{1}$

Yes

$11(40.8) \quad 12(48.0)$

No

$16(59.2) \quad 13(52.0)$

Previous and concomitant betalactam therapy

$\mathrm{NS}^{1}$

Yes $\quad 9(33.4) \quad 8(32.0)$

No

$18(66.6) \quad 17(68.0)$

Daptomycin prescribed dose (mg)

$\mathrm{NS}^{1}$

$\begin{array}{lll}<500 & 0 & 1(4.0)\end{array}$

$\geq 500 \quad 27(100.0) \quad 24(96.0)$

Duration of

daptomycin

therapy (guideline

0.025

indication)

Yes

$7(25.9)$

$1(4.0)$

No

$20(74.1) \quad 24(96.0)$

${ }^{1} \mathrm{NS}=$ not significant; ${ }^{*}$ Fisher's exact test $;{ }^{2} \mathrm{MRSA}=$ methicillinresistant Staphylococcus aureus; ${ }^{3} S$. coagulase negative (S. epidermidis, S. constellatus, and S.capitis) 


\section{Previous and concomitant antibiotic treatment}

Most patients (45 out of 52;86.5\%) received daptomycin as a second-line treatment; the antibiotics prescribed previously were glycopeptides $(37 / 45,82.2 \%$; vancomycin, $\mathrm{n}=33$; and teicoplanin, $\mathrm{n}=4)$, and/or betalactams $(32 / 45,71.1 \%$; piperacillin + tazobactam, $\mathrm{n}=$ 22, meropenem, $n=13$, and oxacillin, $n=6$ ). The first antibiotic had been switched to daptomycin because of treatment failure $(31 / 45 ; 68.9 \%)$ or adverse drug reactions (ADRs; 14/45; 31.1\%).

Only 13 patients of the INTO cohort $(25.0 \%)$ received daptomycin alone. The remaining 39 patients (75.0\%) were prescribed daptomycin in combination with other antibiotics; the most frequent ones were betalactams $(23 / 39 ; 59.0 \%)$ or rifampicin $(9 / 39 ; 23.0 \%)$.

\section{Adherence to guidelines and recommendations}

Table II shows adherence to different aspects of the clinical recommendations for daptomycin use. It is to be noted that daptomycin was selected as a firstline treatment in 7 patients $(13.5 \%)$ and that 8 patients $(15.4 \%)$ received daptomycin to treat synovial fluid infection. None of these situations were recommended.
Up to 5 patients $(9.6 \%)$ had $S$. aureus coagulase negative without data on MIC for daptomycin, and 13 patients $(25.0 \%)$ had infections caused by other pathogens. Thus, in 18 out of 52 patients $(34.6 \%$ of the cohort), the guidelines had not been followed regarding microbiological aspects.

The mean daptomycin prescribed dose was $557 \mathrm{mg} /$ day $(\mathrm{SD}=146.6)$; most patients $(42 ; 80.7 \%)$ were given the standard $500 \mathrm{mg} /$ day dose. Four patients had chronic kidney disease (7.7\%), and the daptomycin dosing regimen had been one dose every 48 hours, according to the recommendations. It is to be noted that neither the body weight nor the body mass index (BMI) were calculated for any patient in this cohort.

Daptomycin was prescribed by infectious disease specialists in 32 out of 52 patients $(61.5 \%)$ of the study cohort. The remaining 20 prescriptions were originated by intensive care physicians $(14 / 52 ; 27.0 \%)$ or general doctors $(6 / 52 ; 11.5 \%)$.

Thus, taking into account the different aspects considered in the clinical recommendations for the use of daptomycin, complete adherence was found in only $15.4 \%$ of the patients of the study $(8 / 52)$.

TABLE II - Adherence to different aspects of the clinical recommendations for daptomycin use and clinical success or failure among the 52 patients. Brazil, 2010-14

\begin{tabular}{|c|c|c|c|c|}
\hline Clinical recommendations & $\begin{array}{l}\text { Clinical success } \\
\quad(\mathbf{N}=\mathbf{2 7})\end{array}$ & $\begin{array}{l}\text { Treatment failure } \\
\qquad(N=25)\end{array}$ & Total & p-value ${ }^{*}$ \\
\hline Indication of use (identification of an organism) & & & & $\mathrm{NS}^{1}$ \\
\hline Recommended & $20(74.0)$ & $13(52.0)$ & 33 & \\
\hline Nonrecommended & $7(26.0)$ & $12(48.0)$ & 19 & \\
\hline Line therapy & & & & $\mathrm{NS}^{1}$ \\
\hline Second & 21(77.8) & $24(96.0)$ & 45 & \\
\hline First & $6(22.2)$ & $1(4.0)$ & 7 & \\
\hline Pathogen & & & & $\mathrm{NS}^{1}$ \\
\hline MRSA $^{2}$ & $19(70.4)$ & $15(60.0)$ & 34 & \\
\hline Others organisms & $8(29.6)$ & $10(40.0)$ & 18 & \\
\hline
\end{tabular}


TABLE II - Adherence to different aspects of the clinical recommendations for daptomycin use and clinical success or failure among the 52 patients. Brazil, 2010-14

\begin{tabular}{|c|c|c|c|c|}
\hline Clinical recommendations & $\begin{array}{l}\text { Clinical success } \\
\qquad(\mathbf{N}=\mathbf{2 7})\end{array}$ & $\begin{array}{l}\text { Treatment failure } \\
\qquad(\mathbf{N}=\mathbf{2 5})\end{array}$ & Total & p-value ${ }^{*}$ \\
\hline Prescriber & & & & 0.053 \\
\hline Infectologist & $20(74.0)$ & $12(48.0)$ & 32 & \\
\hline Others & $7(26.0)$ & $13(52.0)$ & 20 & \\
\hline Previous vancomycin therapy & & & & $\mathrm{NS}^{1}$ \\
\hline Yes & $19(90.0)$ & $10(83.3)$ & 29 & \\
\hline No & $2(10.0)$ & $2(16.7)$ & 4 & \\
\hline $\begin{array}{l}\text { Dose and time therapy (according with } \\
\text { the side of infection and organism) }\end{array}$ & & & & $\mathrm{NS}^{1}$ \\
\hline Recommended & $7(26.0)$ & $5(20.0)$ & 12 & \\
\hline Nonrecommended & $20(74.0)$ & $20(80.0)$ & 40 & \\
\hline
\end{tabular}

${ }^{1} \mathrm{NS}=$ not significant; ${ }^{2} \mathrm{MRSA}=$ methicillin-resistant Staphylococcus aureus; ${ }^{*}$ Chi-square test

\section{Clinical success}

Clinical success or "cure" was achieved by $51.9 \%$ of the patients undergoing therapy with daptomycin (27 out of 52 patients). The proportion of clinical success increased to $59.1 \%$ if only patients treated for osteomyelitis and bacteremia were considered (26 cured out of 44 patients).

Among the clinical success group, the mean duration of treatment with daptomycin was 35 days $(\mathrm{SD}=24.5)$ and the daily dose was $565 \mathrm{mg} /$ day. Just one patient had infection in synovial fluid and was cured; this patient was infected by $S$. aureus coagulase negative.

Among the 25 patients who showed treatment failure $(48.1 \%), 24$ had received previous antibiotic therapy, $67 \%$ with glycopeptides (16/24), vancomycin $(16 / 16)$, and/or teicoplanin (2/16). The mean duration of the therapy with daptomycin was 22 days $(\mathrm{SD}=16.9)$ and the daily dose was $550 \mathrm{mg} /$ day.

The mean duration of the therapy with daptomycin was 28 days $(\mathrm{SD}=16.7)$ in the group with treatment failure and 24 days $(\mathrm{SD}=22.0)$ in the group that found clinical success. Among the 25 patients in the treatment failure group, $52.0 \%$ had the drug prescribed by general doctors or intensive care physicians (Rae, 2014), while among the 27 patients of the clinical success group, $74.0 \%$ had it prescribed by an infectious disease specialist (Montange et al., 2014).

Taken as a whole, patients seem to have more chance of clinical success if the duration of daptomycin therapy was according to guideline indications (OR = $16.86 ; 95 \% \mathrm{CI}=1.45-195.88$ ) and seem to have more chance of success if daptomycin was prescribed by a specialist in infectious diseases $(\mathrm{OR}=4.84 ; 95 \% \mathrm{CI}=$ 1.11-21.09) (Table III).

In this study, five patients ( $9.6 \%$ of the cohort) died. It is interesting to highlight that none had followed the guideline recommendations. Four patients presented osteomyelitis and one bacteremia, two were colonized by MRSA, and the remaining three by Staphylococcus capitis, Staphylococcus epidermidis, and Pseudomonas aeuroginosa (1 patient each). Their comorbidities included hypertension (3 patients) and obesity and vestibular disease (1 each). In this group, just 1 
patient had not been treated with vancomycin, and the daptomycin prior to the dose used was $500 \mathrm{mg} / \mathrm{kg} /$ day.

TABLE III - Logistic regression analysis of variables associated with success in the 52 orthopedic patients undergoing therapy with daptomycin. Brazil, 2010-14

\begin{tabular}{lcc}
\hline Variable & Odds ratio* $^{*}$ & $\begin{array}{c}\text { 95\% confidence } \\
\text { interval }\end{array}$ \\
\hline Underlying disease & 0.52 & $0.05-4.69$ \\
$\begin{array}{l}\text { Types of infection } \\
\begin{array}{l}\text { Duration of daptomycin } \\
\text { therapy (guideline }\end{array}\end{array}$ & 0.46 & $0.06-2.83$ \\
$\begin{array}{l}\text { indication) } \\
\text { Prescriber: Infectologist }\end{array}$ & 4.84 & $1.45-195.88$ \\
\hline
\end{tabular}

"Logistic regression model

\section{DISCUSSION}

The analysis of the 52 patients treated with daptomycin that constituted the INTO cohort showed clinical success in $51.8 \%$ of the cases. This proportion is clearly lower than those reported in other published cohorts, which ranged from $71.0 \%$ to $96.0 \%$ of treated patients (Seaton et al., 2013; Fossaseca, 2007). A closer look at the INTO patients also showed $87.5 \%$ clinical success (7/8 patients) among those strictly following the clinical guidelines, and only $45.5 \%$ clinical success among those who did not follow the clinical recommendations. This result is important, because it shows the actual use of an allegedly reserve antibiotic in the daily practice of a specialized hospital, far from the methodological conditionings of some published study cohorts such as the Cubicin Registry and Experience (CORE) and EUCORE (Vilhena, Bettencourt, 2012; Gonzalez-Ruiz et al., 2011; Marc et al., 2014; Seaton et al., 2013; Timerman et al., 2013).

Retrospective studies that investigated the guideline for daptomycin use found $65.0-75.0 \%$ clinical success (Holtom et al., 2007; Lamp et al., 2007).

A French study that investigated the use of aminoglycosides but did not use daptomycin yielded a different result about the use of the guidelines. This study showed that $65.2 \%$ of patients had a clinical indication but that the guideline for the drugs was followed just in $23.2 \%$ of the cases. The evaluation still showed that the guideline found drug concentration at the peak and trough aminoglycoside in $24.9 \%$ and $67.4 \%$ of the cases, respectively. This study reinforces the use of the guideline, especially in cases with a high risk of underdosing (Robert et al., 2017).

Another study that investigated Dutch guidelines for patients with urinary tract infections and that used catheters compared to empirical therapy found that the inadequate coverage of the guideline ranged from $3.0 \%$ to $24.0 \%$ for patients using a catheter. Patients submitted to the guideline presented a broader spectrum, but the continuous epidemiological changing of the resistance rates reinforces the need to improve the adherence to the guideline to increase coverage rates (Spoorenberg et al., 2013).

A 2010 retrospective study at the Bichat-ClaudeBernard teaching hospital in Paris that observed the evolution of daptomycin prescriptions showed that $95 \%$ of daptomycin prescriptions were off-label, most did not comply with local guidelines, and more than a half of the treatments were prescribed both off-label and not according to local recommendations (Marc et al., 2014).

As an antibiotic with high efficacy and a good safety profile, according to published studies showing a tendency to use daptomycin empirically in cases with clear and restrictive indications both in the EMA, FDA, and ANVISA SPCs and MRSA osteomyelitis, a study that analyzed patients who received daptomycin after failed with previous treatment found clinical success for all nine patients, but one relapsed, thus $89.0 \%$ had clinical success (Finney, Crank, and Segreti, 2005).

In order to be as comprehensive as possible, MRSA osteomyelitis was considered as an "approved" or "allowed" indication, taking into account the microbiological causal agent in the INTO cohort; otherwise a more restrictive analysis following the Brazilian recommendations would have reduced adherence to the recommendations even more.

An additional interesting practical observation is that the INTO cohort included hospitalized orthopedic patients; these were patients with low or no mobility and prolonged hospital stays, which makes difficult to know their weight and BMI. As dosage recommendations are based on BMI calculations, none of the included patients could strictly follow the guideline. 
So, considering adherence to the guideline, dosage individualization was considered to be "calculated according the recommendations" in all cases. The fact was that, in the INTO cohort, the dosage was calculated from a standard estimated weight of $75-80 \mathrm{~kg}$. This could also explain part of the treatment failure observed in the cohort of patients, because unadjusted dosages by body weight or BMI could result in doses below those needed. Due to the frequency of infections produced by daptomycin-susceptible microorganisms in patients with poor mobility, this factor should be taken into account in the recommendations for use and in future studies.

Up to eight patients received daptomycin for a synovial fluid infection, of which seven experienced treatment failure. This is an unapproved indication of use even if it is caused by MRSA, and, to our knowledge, the only published evidence is a study with 16 healthy volunteers that showed a $54.0 \%$ concentration of daptomycin in synovial fluid after infusion of $8 \mathrm{mg} / \mathrm{kg}$ (Sakoulas et al., 2009). This use seems an extrapolation of results, something that could be frequent in real clinical practice but that should be avoided.

Finally, five patients died while they were on treatment with daptomycin. All of them were complicated, with longer hospitalization. Due to the characteristics of the source database, it is not possible to establish or to rule out any causal relationship. The main point here is that none of these patients had been prescribed daptomycin according to any recommendation of use.

Clinical success can improve when the antibiotics are prescribed by specialists (Rae, 2014; Esposito et al., 2016). A study that evaluated treatments and results before and after specialist consultations that applied the guideline found an increase of specific results, negative cultures, and an improvement in diagnosis and therapy appropriateness, with statistical significance $(\mathrm{p}<0.001)$ (Esposito et al., 2016).

All these findings point to the need to reinforce clinical guidelines and recommendations in some aspects: (1) to ensure that these guidelines and recommendations are coherent with the most relevant published evidence; (2) to strengthen the implementation process of any new guideline or recommendation of use once a new medicine is included in a hospital formulary; and (3) to encourage potential prescribers to adhere to clinical guidelines in order to avoid treatment failure, unnecessary side effects, or inefficient expenditures.

The limitations of the present study are its observational and retrospective design, in that some missing or inaccurate information in the clinical charts could have biased the results presented herein. This could be the case for the five patients who died, as a recorded cause of death was the unspecific "cardiorespiratory arrest." On the other hand, the observational character of the study has obvious advantages for analyzing the behavior of prescribers in noncontrolled and real day-to-day clinical activity. Besides this, the lack of drug sensitivity of the bacteria involved was not investigated and would be important for future studies. Off-label prescriptions must respect some conditions to be considered acceptable (e.g., no available alternative drug, "indispensability" as judged by the prescriber, and free and informed patient consent) (Marc et al., 2014). None of these conditions were explicitly present in the INTO cohort. Thus, despite their limitations, observational studies complement the experimental ones and help to identify processes and decisions that can improve research.

As happens with many drug utilization studies, the external validity of the results can be questioned. Notwithstanding this, drug utilization studies are useful to raise problems that can be addressed in the hospital where the study was carried out and at the same time, identify potential causes of therapeutic failure that could be investigated in other clinical settings. Especially in this research, the results reinforce the importance of the guideline for using daptomycin.

Despite well-defined conditions for using daptomycin, there are different aspects that could favor more generalized and inappropriate use or even off-label use of this antibiotic agent. The published evidence describing high rates of success, an acceptable safety profile, and good to excellent blood, urine, and joint concentrations could contribute to this generalized use. Inappropriate use of a second-line antibiotic such as daptomycin, in addition to its excessive and unnecessary cost, can increase the appearance of resistant pathogens, a growing and worrying problem all over the world.

The inappropriate use of medicines is a global phenomenon, and it should be taken into account as a factor contributing to the clinical failure of a given active ingredient.

\section{CONCLUSIONS}

This study shows that patients have more of a chance of clinical success with daptomycin when the therapy follows the guideline indications and when daptomycin is prescribed by a specialist in infectious diseases. 
Regarding adherence to guidelines, the dosage of the antibiotic had to be prescribed by applying a standard estimated weight of $75-80 \mathrm{~kg}$ as it is challenging to measure the weight or calculate the BMI of orthopaedic patients. So, none of the included patients could strictly follow the guideline. Because of that, doses could have been unadjusted for body weight or BMI, and below the doses needed, which would have impacted on the infections. These aspects are important for minimizing early resistance to reserve antibiotics and adverse reactions due to a drug that may not have been the most suitable for a given patient, to avoid unnecessarily elevated pharmacy expenditures, and to promote better use of medicines.

Adhering to treatment recommendations, the dosage of the antibiotic was prescribed by applying a standard estimated weight of $75-80 \mathrm{~kg}$ because it is very difficult to measure the weight or calculate the BMI of orthopedic patients. So, none of the included patients could strictly follow the guideline. Because of that, doses could have been unadjusted for body weight or BMI, and below the doses needed, which would have impacted on the infections.

These aspects are important for minimizing early resistance to reserve antibiotics and adverse reactions due to a drug that may not have been the most suitable for a given patients, to avoid unnecessary elevated pharmacy expenditures, and to promote a better use of medicines.

\section{ACKNOWLEDGMENTS}

Coordination of Improvement of Higher Education Personnel (CAPES/Brazil) to support the sandwich program of Tathiana Silva de Souza Martins at the Catalan Foundation Institute of Pharmacology (Barcelona, Spain).

\section{CONFLICTS OF INTEREST}

None.

\section{REFERENCES}

Agência Nacional de Vigilância Sanitária. Anvisa (ANVISA). Cubicin (daptomicina) Novartis Biociências SA Pó para solução para injeção ou infusão 500 mg, 2017 [Internet]. Available from: http://www. anvisa.gov.br/datavisa/fila_bula/frmVisualizarBula. asp?pNuTransacao $=10318902013 \&$ pIdAnexo $=1895272$
Cosgrove SE, Avdic E, Dzintars K. Antibiotic Guidelines 2015-2016 - Treatment Recommendations for Adult Inpatients [Internet]. Johns Hopkins Hospital. Antimicrobial Stewardship Program, 2015. [cited 2018 Jan 09]. 164 p. [cited 2018 Jan 09]. Available from: insidehopkinsmedicine.org/amp

Davis JS. Management of bone and joint infections due to Staphylococcus aureus. Int Med J. 2005;35(Suppl):79-96.

Esposito S, Russo E, Simone G, Gioia R, Petta E, Leone S, et al. Diagnostic and therapeutic appropriateness in bone and joint infections: results of a national survey. J Chemother. 2016;28(3):191-197.

European Medicines Agency. [Internet]. Cubicin daptomycin, 2009. [cited 2018 Jan 09]. Available from: http://www.ema.europa.eu/ema/index.jsp?curl=pages/ medicines/human/medicines/000637/human_med_000730. jsp\&mid=WC0b01ac058001d124.

Finney MS, Crank CW, Segreti J. Use of daptomycin to treat drug resistant gram-positive bone and joint infections. Curr Med Res Opin. 2005;21(12):1923-6.

Fossaseca C. Outcomes analysis of daptomycin use in a community hospital. Adv Ther. 2007;24(3):517-528.

Gonzalez-Ruiz A, Beira-Fernandez A, Lehmkuhl H, Seaton RA, Loeffler J, Chaves RL. Clinical experience with daptomycin in Europe: the first 2.5 years. J Antimicrob Chemother. 2011;66(4):912-919.

He W, Zhang Y, Chen H, Zhao C, Wang H. Efficacy and safety of daptomycin for the treatment of infectious disease: a metaanalysis based on randomized controlled trials. J Antimicrob Chemother. 2014;69(12):3181-3189.

Holtom PD, Zalavras CG, Lamp KC, Park N, Friedrich LV. Clinical experience with daptomycin treatment of foot or ankle osteomyelitis: a preliminary study. Clin Orthop Relat Res. 2007;461:35-9.

Lamp KC, Friedrich LV, Mendez-Vigo L, Russo R. Clinical experience with daptomycin for the treatment of patients with osteomyelitis. Am J Med. 2007;120(10 Suppl 1):S13-20.

Liang SY, Khair HN, McDonald JR, Babcock HM, Marschall J. Daptomycin versus vancomycin for osteoarticular infections due to methicillin-resistant Staphylococcus aureus (MRSA): a nested case-control study. Eur J Clin Microbiol Infect Dis. 2014;33(4):659-664.

Liu C, Bayer A, Cosgrove SE, Daum RS, Fridkin SK, Gorwitz $\mathrm{RJ}$, et al. Clinical practice guidelines by the Infectious Diseases Society of America for the treatment of methicillin- 
resistant Staphylococcus aureus infections in adults and children. Clin Infect Dis. 2011;52(3):e18-55.

Marc F, Esquirol C, Papy E, Longuet P, Armand-Lefevre L, Rioux C, et al. A retrospective study of daptomycin use in a Paris teaching-hospital. Med Mal Infect. 2014;44(1):25-31.

Moenster RP, Linneman TW, Finnegan PM, Mcdonald JR. Daptomycin compared to vancomycin for the treatment of osteomyelitis: a single-center, retrospective cohort study. Clin Ther. 2012;34(7):1521-1527.

Montange D, Berthier F, Leclerc G, Serre A, Jeunet L, Berard M, et al. Penetration of Daptomycin into Bone and Synovial Fluid in Joint Replacement. Antimicrob Agents Chemother. 2014;58(7):3991-3996.

Rae N. NHS. Daptomycin prescribing guidance [Internet]. NHS Tayside, 2014. [cited 2018 Jan 09]. 03 p. Available from: http://www.nhstaysideadtc.scot.nhs.uk/Antibiotic\%20site/ pdf\%20docs/Daptomycin\%20policy\%20final\%202014.pdf.

Rice DAK, Vigo LM. Daptomycin in bone and joint infections: a review of the literature. Arch Orthop Trauma Surg. 2009;129(11):1495-1504.

Robert J, Péan Y, Alfandari S, Bru JP, Bedos JP, Rabaud C. Application of guidelines for aminoglycosides use in French hospitals in 2013-2014. Eur J Clin Microbiol Infect Dis. 2017;36(7):1083-1090.

Sakoulas G. Clinical outcomes with daptomycin: a postmarketing, realworld evaluation. Clin Microbiol Infect. 2009;15(Suppl 6):11-16.
Sakoulas G, Brown J, Lamp KC, Friedrich LV, Lindfield KC. Clinical Outcomes of Patients Receiving Daptomycin for the Treatment of Staphylococcus aureus Infections and Assessment of Clinical Factors for Daptomycin Failure: A Retrospective Cohort Study Utilizing the Antimicrobial Agents and Chemotherapy Cubicin ${ }^{\circledR}$ Outcomes Registry and Experience. Clin Ther. 2009;31(9):1936-1945.

Seaton RA, Malizos KN, Viale P, Gargalianos-Kakolyris P, Santantonio T, Petrelli E, et al. Daptomycin use in patients with osteomyelitis: a preliminary report from the EU-CORE(SM) database. J Antimicrob Chemother. 2013;68(7):1642-1649.

Vilhena C, Bettencourt A. Daptomycin: a review of properties, clinical use, drug delivery and resistance. Mini Rev Med Chem. 2012;12(3):202-209.

Spoorenberg V, Prins JM, Stobberingh EE, Hulscher ME, Geerlings SE. Adequacy of an evidence-based treatment guideline for complicated urinary tract infections in the Netherlands and the effectiveness of guideline adherence. Eur J Clin Microbiol Infect Dis. 2013;32(12):1545-1556.

Timerman A, Brites C, Bicudo E, Costa Filho R, Carrilho $\mathrm{CD}$, et al. Brazilian experience in EU-CORE: daptomycin registry and treatment of serious Gram-positive infections. Braz J Infect Dis. 2013;17(6):647-653.

Received for publication on $07^{\text {th }}$ April 2017 Accepted for publication on $15^{\text {th }}$ January 2019 